\title{
Annulenes
}

\section{A Direct One-Pot Synthesis of Asymmetric Dehydrobenzopyrido- [12]annulenes and Their Physicochemical Properties}

\author{
Paul N. W. Baxter, ${ }^{*[a]}$ Lydia Karmazin, ${ }^{[b]}$ André DeCian, ${ }^{[b]}$ Alexandre Varnek, ${ }^{[b]}$ \\ Jean-Paul Gisselbrecht, ${ }^{[b]}$ Jean-Marc Strub, ${ }^{[c]}$ and Sarah Cianferani ${ }^{[c]}$
}

\begin{abstract}
A direct one-pot synthesis of asymmetric dehydrobenzopyrido[12]annulenes $\mathbf{2}$ and $\mathbf{3}$ containing one or two pyridine rings is reported that employs a Stephens-Castro mediated cross-coupling of mixtures of ethynylcuprate precursors. The spectroscopic and theoretical properties of $\mathbf{2}$ and $\mathbf{3}$ are compared to those of the threefold symmetric dehydrotribenzo[12]annulene 1, and dehydrotripyrido[12]annulenes 4 and $\mathbf{5}$ and dehydrodibenzodipyrido[16]annulene byproduct $\mathbf{6}$,
\end{abstract}

and showed 1-5 to be essentially isoelectronic band gap materials whose electron accepting ability increases with increasing nitrogen incorporation. The structures of 2, $\mathbf{4}$ and $\mathbf{6}$ were also unambiguously characterized by X-ray crystallography. The results highlight the potential dehydroaryl[12]annulenes incorporating pyridines offer for the construction of high carbon content electronic materials.

\section{Introduction}

Dehydrotribenzo[12]annulene ${ }^{[1]}$ ([12]DBA, 1, Scheme 1) is a hydrocarbon macrocycle with a unique conjugated architecture $\mathrm{e}^{[2,3]}$ that represents the smallest substructure of graphyne, the hypothetical expanded carbon network predicted to possess many intriguing mechanical and physicochemical properties. ${ }^{[4-9]}$ Indeed, hints at the materials science potential of $\mathbf{1}$ were first noted in mid-1980s when it was found to form metal sandwich complexes with possible molecular electronics applications. ${ }^{[10-12]}$ And, although a renewed interest in carbon allotropes has led to the preparation of multiply fused [12]DBAs as model systems for the study of graphyne, ${ }^{[13-21]}$ comparatively little progress has been made concerning the construction of well-defined carbon polymer networks incorporating 1. By contrast, hydrocarbon chain-functionalized analogues of $\mathbf{1}$, have been shown to constitute a wellspring of novel network materials held together by Van der Waals interactions. ${ }^{[22-26]}$ The most noteworthy examples of the latter comprise networks that include nanosized guests $^{[27-29]}$ and form chiral surfaces, ${ }^{[30]}$ as well as networks capable of photomanipulation ${ }^{[31]}$ and those exhibiting quantum confinement of electrons. ${ }^{[32]}$ Helical ${ }^{[33]}$ and stacked columnar hydrogen bonded [12]DBA arrays ${ }^{[34]}$ have also been prepared, as

[a] Institut Charles Sadron, UPR 22-CNRS-UdS,

23 rue du Loess, 67034 Strasbourg, France

E-mail: baxter@unistra.fr

http://www-ics.u-strasbg.fr

[b] Institut de Chimie de Strasbourg, UMR 7177 CNRS-UdS, 1 rue Blaise Pascal, 67008 Strasbourg, France

[c] Laboratoire de Spectrométrie de Masse Bio-Organique, Département des Sciences Analytiques IPHC, UMR 7178 (CNRS-UdS) ECPM, 25 rue Becquerel, 67087 Strasbourg, France

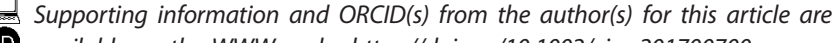
available on the WWW under https://doi.org/10.1002/ejoc.201700700. well as mesoporous covalent organic networks, which function as gas adsorption media. ${ }^{[35,36]}$

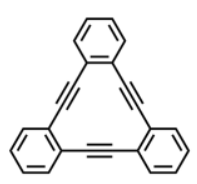

1

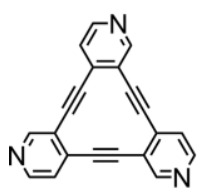

4

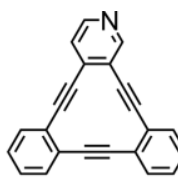

2

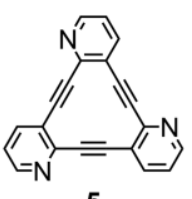

5

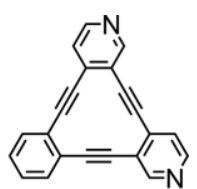

3

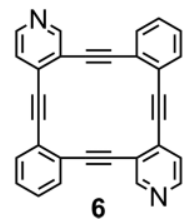

Scheme 1.

As a result of the revived interest in 1, an expanded range of synthetic methods have been developed for the preparation of functionalized [12]DBAs that comprise two main categories; (a) one-pot cyclotrimerization reactions, and (b) stepwise reactions, in which final ring closure is effected upon hetero-combination of two precursors, or intramolecular ring closure of a preformed oligomer. The one-pot cyclotrimerization reaction has been the most frequently used method for the syntheses of symmetrically functionalized [12]DBAs, often using the conditions reported for the Stephens-Castro cyclotrimerization synthesis of $\mathbf{1}$ essentially in its originally published form. ${ }^{[37-40]}$ In this latter case, the ${ }^{-}$ iodoethyne precursor is usually treated with $\mathrm{CuSO}_{4} / \mathrm{NH}_{2} \mathrm{OH} \cdot \mathrm{HCl}$ in $\mathrm{EtOH} / \mathrm{H}_{2} \mathrm{O}$ and then the precipitated organocuprate heated in pyridine to effect cyclization. However, the adaptation of lyoda et al., ${ }^{[18]}$ using $\mathrm{K}_{2} \mathrm{CO}_{3}$ as base and added $\mathrm{PPh}_{3}$ ligand in $\mathrm{DMF}$, has currently become more popular. ${ }^{[34,41-43]}$ Sonogashira-Hagihara 
conditions $^{[44,45]}$ have also been successfully utilized with sensitive substrates, although the cyclization yields are often low. ${ }^{[13,15,29,30,38,42]}$

With respect to stepwise reactions, 1 has been prepared by the Stephens-Castro-mediated coupling of a di-ethynylcuprate and 1,2-diiodobenzene ${ }^{[46]}$ and substituted [12]DBAs via Sonogashira-Hagihara coupling of a diiodo-triaryl precursor and acetylene gas as well as from substituted di- and tetrahalo-tolane and diethynylbenzene precursors. ${ }^{[15,47,48]}$ Intramolecular ring-closing strategies include the Wittig methodology employed by Staab et al., ${ }^{[4,50]}$ as well as Sonogashira-Hagihara coupling, ${ }^{[21,51]}$ ethyne metathesis ${ }^{[13,16]}$ and aldehyde coupling approaches. ${ }^{[14,17]}$

During part of our studies on the generation of dehydrotriaryl[12]annulene-based coordination polymers, which necessitated the synthesis of the symmetric dehydrotripyrido[12]annulene 4 (Scheme 1), ${ }^{[52]}$ we also required samples of the asymmetric dehydrotriaryl[12]annulenes $\mathbf{2}$ and $\mathbf{3}$ incorporating one and two pyridyl rings respectively (Scheme 1). With these compounds in hand, we could determine if the FMO band gaps were amenable to alteration and tuning by successive incorporation of nitrogen atoms into the [12]DBA system, and also to use them as ligands for the assembly of novel types of coordination architectures with interesting electronic and photophysical properties. However, despite the current interest in symmetrically trifunctionalized [12]DBAs with increasing degrees of structural complexity, the preparation of asymmetrically substituted [12]DBAs has been largely ignored in the literature, ${ }^{[13,47]}$ which is surprising considering their potential as building blocks for the assembly of larger entities and polymers, and as novel materials in their own right.

Although multistep approaches would normally be considered to be the best method of synthesis of asymmetric [12]DBAs, they suffer inherent limitations such as costs in time and low overall yields. We therefore reasoned that a more direct access to asymmetric [12]DBAs would be to employ one-pot cyclotrimerization reactions with mixtures of starting 2-iodo-ethynylarenes under Stephens-Castro conditions that may afford statistical mixtures of symmetric and asymmetric [12]DBAs. In the case of polar substituents, the asymmetric [12]DBAs should be separable using conventional column chromatography. As the cyclization yield of our previously reported synthesis of $\mathbf{4}$ using the original Stephens-Castro conditions was very low, ${ }^{[52]}$ we therefore decided to prepare $\mathbf{2}$ and $\mathbf{3}$ together in one pot using a mixed Stephens-Castro coupling under modified anhydrous conditions previously found successful for the direct syntheses of hexaalkoxy-substituted dehydrotribenzo[12]annulenes. ${ }^{[38]}$

Accordingly, we found that a mixed-coupling approach did indeed provide direct one-pot access to $\mathbf{2}$ and $\mathbf{3}$ in low-to-moderate yields that could be adjusted by varying the relative proportions of starting 2-iodo-ethynylarenes. Following the successful direct generation and isolation of $\mathbf{2}$ and $\mathbf{3}$, it was then possible to compare the physicochemical and theoretical properties of these macrocycles with those of the symmetric analogues $\mathbf{1}$, $\mathbf{4}$ and $\mathbf{5}$ as well as the dehydrodibenzodipyrido[16]annulene $\mathbf{6}$, a reaction byproduct isolated from the mixed coupling (Scheme 1), and thereby reveal the overall electronic properties of the complete series of dehydroaryl[12]annulenes $\mathbf{1 - 5}$ with respectively zero, one, two and three pyridine rings. The results of these investigations are detailed below.

\section{Results and Discussion}

\section{Generation of Asymmetric Dehydrotriaryl[12]annulenes 2 and 3 through a Mixed-Coupling Stephens-Castro Mediated Cyclotrimerization}

As detailed above, the preparation of asymmetrically functionalized [12]DBAs that are not part of larger fused multi-ring structures have rarely been attempted despite hints at intriguing physicochemical properties and potential uses as versatile [12]DBA building blocks. Furthermore, they were synthesized via circuitous multistep procedures that limit ready access to such materials. ${ }^{[47]}$ We therefore explored the feasibility of using a direct method of preparation of asymmetric heteroaromatic $\mathbf{2}$ and 3 (Scheme 2) via a one-pot mixed Stephens-Castro coupling reaction of cuprates $\mathbf{8}$ and 10, which were generated in situ using $t \mathrm{BuOCu}$ as the metallation reagent in pyridine. ${ }^{[38,53]}$ The distribution of yields of 1-4 isolated from the reactions investigated are shown in Table 1.

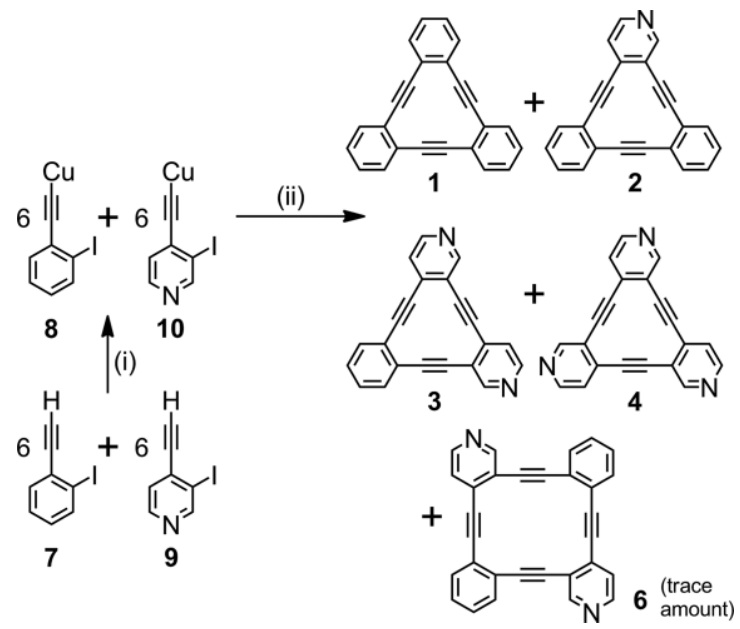

Scheme 2. One-pot Stephens-Castro mediated mixed cyclotrimerization of a mixture of $\mathbf{8}$ and 10, generated from 7, 9, Cul and $t$ BuOK in pyridine (i), followed by heating at $140{ }^{\circ} \mathrm{C}$ for $24 \mathrm{~h}$ (ii).

Table 1. Isolated yield distributions of 1-4 from the Stephens-Castro mediated cyclotrimerizations of mixtures of ethynylcuprates 8 and 10, generated from one-pot reactions comprising 7, 9, Cul and $t \mathrm{BuOK}$.

\begin{tabular}{llllll}
\hline Entry & $\begin{array}{l}\text { Molar ratio of reactants } \\
\text { 7/9/Cul/tBuOK }\end{array}$ & $\begin{array}{l}\text { Yield } \mathbf{1} \\
{[\%]}\end{array}$ & $\begin{array}{l}\text { Yield } \mathbf{2} \\
{[\%]}\end{array}$ & $\begin{array}{l}\text { Yield } \mathbf{3} \\
{[\%]}\end{array}$ & $\begin{array}{l}\text { Yield } \mathbf{4} \\
{[\%]}\end{array}$ \\
\hline 1 & $1: 1: 2: 2$ & $13(50)$ & $19(38)$ & $21(41)$ & $5(22)$ \\
2 & $2: 1: 3: 3$ & 25 & 16 & 15 & $<1$ \\
3 & $4: 1: 5: 5$ & 34 & 27 & 10 & 0 \\
\hline
\end{tabular}

All reactions were conducted under identical conditions and concentrations in pyridine (see Experimental Methods) employing the same quantity of iodopyridylethyne $\mathbf{9}$, while increasing the relative amount of iodophenylethyne $\mathbf{7}$ from a $\mathbf{7 / 9}$ ratio of 1:1 to $4: 1$ (entries $1-3$, Table 1). The quantities of $\mathrm{Cul}$ and $t \mathrm{BuOK}$ 
were adjusted to ensure an equimolar ratio of $t \mathrm{BuOCu} / \mathbf{7}+\mathbf{9}$ to form ethynylcuprates $\mathbf{8}$ and $\mathbf{1 0}$. The yields are expressed as a percentage of the maximum theoretical yields obtainable for each product.

A statistical 1:1 reaction would proceed according to the following stoichiometry: $12(\mathbf{8})+12(\mathbf{1 0}) \rightarrow(\mathbf{1})+3(\mathbf{2})+3(\mathbf{3})+$ (4). The yields shown in parentheses for the 1:1 reaction of $\mathbf{8 / 1 0}$ (entry 1, Table 1) are expressed as a percentage of the theoretical yields of products calculated for the 1:1 stoichiometric equation above. As these theoretical yields (i.e. the statistical theoretical yields) are lower than maximum non-statistical theoretical yields, the percent yields in parentheses of entry 1 of Table 1 are higher.

A detailed inspection of the X-ray crystal structures of ethynylcuprates shows that these form highly organized polymeric, chain and cyclic structures in the solid state due to supramolecular T-shaped organometallic interactions between the $\mathrm{Cu}^{\mathrm{l}}$ and ethyne $\pi$-orbitals. ${ }^{[54]}$ This raises the possibility that the ethynylcuprates $\mathbf{8}$ and $\mathbf{1 0}$ may also form organized supramolecular assemblies in solution that may also exhibit varying degrees of homo- and/or hetero-recognition, as is commonly encountered with metal-directed self-assembled systems. If such effects were to be operative in our case, then they would be expected to influence the outcome of the mixed coupling reactions and thus the distribution of reaction products. For example, entirely homo-recognition between $\mathbf{8}$ and $\mathbf{1 0}$ would yield $\mathbf{1}$ and $\mathbf{4}$ only, whereas exclusive hetero-recognition would afford only $\mathbf{2}$ and $\mathbf{3}$. An entirely statistical reaction between a $1: 1$ ratio of $\mathbf{8}$ and $\mathbf{1 0}$ would give a 1:3:3:1 distribution of 1/2/3/4

In entry 1 of Table 1 , yields greater than the statistical theoretical yields were not observed, ruling out preferential homo- or hetero-association of $\mathbf{8}$ and $\mathbf{1 0}$. However, the lower yield of $\mathbf{4}$ relative to 1 in the 1:1 reaction of entry 1 (Table 1 ) reflects the generally lower yields obtained for $\mathbf{4}$ compared to $\mathbf{1}$ when these compounds are synthesized separately. Increasing the ratio of 7/9 from 1:1 to 4:1 resulted in an overall increase in the yield of mono-pyridyl derivative $\mathbf{2}$, but a successive decrease in the yields of the dipyridyl and tripyridyl derivatives $\mathbf{3}$ and $\mathbf{4}$, as expected for progressive enrichment of the reaction in ethynylcuprate $\mathbf{8}$. Thus the absence of dominating homo-association of ethynylcuprate components enables mixed cyclizations to occur, with yield distributions that can be biased towards particular asymmetric dehydrotriaryl[12]annulenes by varying the ratios of the ethynylcuprate reactants.

When the mixed reaction was conducted with a 1:2 ratio of $\mathbf{7 / 9}$, the yield of $\mathbf{3}$ was not significantly improved over that of the 1:1 reaction of entry 1 (Table 1). The lower cyclization yield of the $\mathbf{9} \rightarrow \mathbf{4}$ reaction mentioned above (due to decompositional sensitivity) may work against an increase in the yield of $\mathbf{3}$ which would otherwise have been expected with an excess of 9. Although the apparent yield limit of $\mathbf{3}$ was only based upon one run, the statistical approach to asymmetric dehydrotriaryl[12]annulenes may be limited in the case of decompositionally sensitive systems.

Interestingly, a trace of $\mathbf{6}$ incorporating two pyridine and two benzene rings (Scheme 2) was also isolated from the purification of $\mathbf{3}$ in the reaction of entry 3, Table 1; the crystal structure of which is described below.

\section{Theoretical Calculations on 1-6}

In order to assess the conjugative and electronic effects of nitrogen heteroatom incorporation into 1, density functional theoretical (DFT) calculations were performed on $\mathbf{1}^{[42]}$ to $\mathbf{5}$, and also 6 for comparison, at the B3LYP level of theory and employing the 6-31G* basis set. ${ }^{[55,56]}$

The frontier molecular orbital (FMO) band gaps calculated for 1-6 (Scheme 3) show that a stepwise increase of nitrogen incorporation into 1 has a negligible effect upon the HOMO-LUMO energy gap and thus the degree of cyclic $\pi$-conjugation within the dehydrotriaryl[12]annulene system.

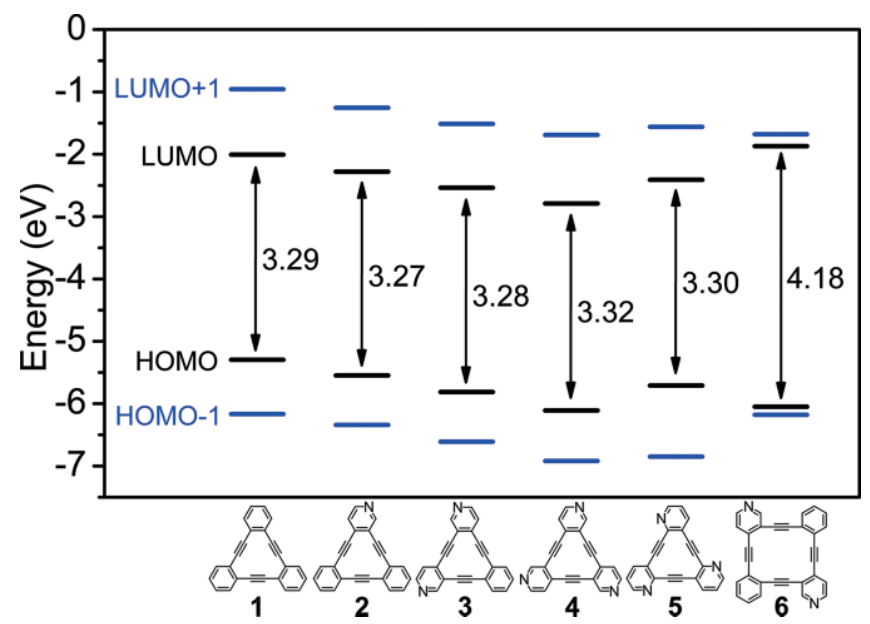

Scheme 3. FMO energy levels and band gaps obtained from DFT calculations on 1-6 at the B3LYP/6-31G* level of theory.

This conclusion was confirmed experimentally upon inspection of the UV/Vis spectra of 1-4, which exhibited overlapping lowest energy absorption edges (Figure 1) that afforded similar optical band gaps (Table 2). ${ }^{[57]}$ However, the calculated energies of both HOMOs and LUMOs decrease proportionally in the following order $\mathbf{1}>\mathbf{2}>\mathbf{3}>\mathbf{4}$ in line with increasing nitrogen incorporation causing increasing electron accepting ability (Scheme 3).

In comparison to the calculated FMOs reported for [12]DBAs with external substituents, the LUMO and HOMO energies of $\mathbf{4}$ ( -2.79 and $-6.11 \mathrm{eV}$ respectively), the most electron accepting system within our dehydrotriaryl[12]annulene series, correspond most closely to those reported for hexafluorodehydrotribenzo[12]annulene, (-2.97 and $-6.20 \mathrm{eV}$ respectively). ${ }^{[2]}$

The tripyrido-isomer $\mathbf{5}$ with 2,3-pyridyl cyclic connectivity on the other hand, was found to be less electron accepting than $\mathbf{4}$ (3,4-pyridyl cyclic connectivity) with calculated FMOs lying between $\mathbf{2}$ and 3, i.e. the [12]DBAs incorporating one and two pyridines respectively. DFT calculations on the dehydrodibenzodipyrido[16]annulene $\mathbf{6}$ revealed that it had the highest energy LUMO and thus largest HOMO-LUMO energy gap within the series of macrocycles studied in this work. This is consistent with its non-planar structure and consequentially inferior cyclic conjugation compared to the planar [12]DBAs.

The FMO surfaces calculated for $\mathbf{1 - 5}$ (Figure 2 and Supporting Information) all exhibit electronic delocalization of the carbon orbitals comprising the inner $12-\pi$ macrocyclic rings. 

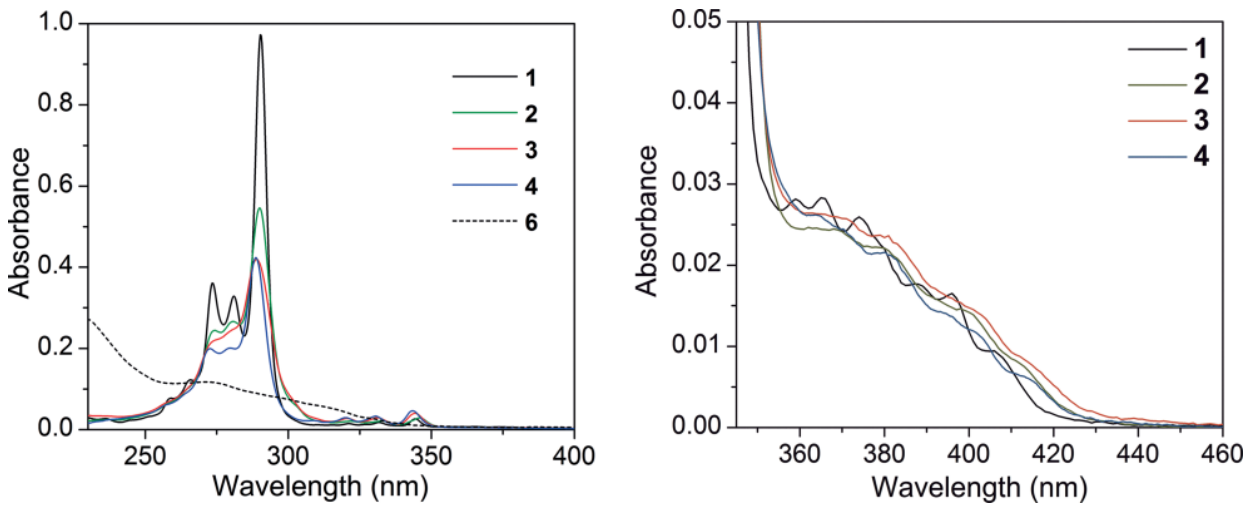

Figure 1. UV/Vis spectra of 1-4 and 6 recorded at $2.6 \times 10^{-6} \mathrm{~mol} \mathrm{~L}^{-1}$ in $\mathrm{CH}_{2} \mathrm{Cl}_{2}$ solution; and expansion of the lowest energy absorption edges of the UV/Vis spectra of 1-4 recorded at $1.3 \times 10^{-5} \mathrm{~mol} \mathrm{~L}^{-1}$ in $\mathrm{CH}_{2} \mathrm{Cl}_{2}$ solution, showing the similarities in line-shape and energy.

Table 2. Comparison of the theoretically calculated FMO band gaps of 1-5 and $\mathbf{6}$ with the experimentally determined optical band gaps $\left(E_{\mathrm{g}}{ }^{\mathrm{opt}}\right)$ obtained from the UV/Vis spectra of 1-4 and $\mathbf{6}$ both in concentrated solution and as thin films.

\begin{tabular}{|c|c|c|c|c|c|c|}
\hline Cycle & $\begin{array}{l}\text { No. of nitrogen } \\
\text { atoms }\end{array}$ & $\begin{array}{l}\mathrm{HOMO} \\
E[\mathrm{eV}]\end{array}$ & $\begin{array}{l}\text { LUMO } \\
E[\mathrm{eV}]\end{array}$ & $\begin{array}{l}\text { (LUMO - HOMO) } \\
\Delta E[\mathrm{eV}]\end{array}$ & $\begin{array}{l}E_{\mathrm{g}}^{\mathrm{opt} \text { soln. }} \\
{[\mathrm{eV}]^{[\mathrm{a}]}}\end{array}$ & $\begin{array}{l}E_{\mathrm{g}}{ }^{\text {opt solid }} \\
{[\mathrm{eV}]^{[\mathrm{b}]}}\end{array}$ \\
\hline 1 & 0 & -5.30 & -2.01 & 3.29 & 2.96 & 2.81 \\
\hline 2 & 1 & -5.55 & -2.28 & 3.27 & 2.91 & 2.83 \\
\hline 3 & 2 & -5.81 & -2.54 & 3.28 & 2.89 & 2.79 \\
\hline 4 & 3 & -6.11 & -2.79 & 3.32 & 2.91 & 2.91 \\
\hline 5 & 3 & -5.71 & -2.41 & 3.30 & - & - \\
\hline 6 & 2 & -6.05 & -1.87 & 4.18 & 3.68 & 3.49 \\
\hline
\end{tabular}

[a] Measured from a spectroscopically concentrated solution in $\mathrm{CH}_{2} \mathrm{Cl}_{2}$ at $6.6 \times 10^{-4} \mathrm{~mol} \mathrm{~L}^{-1}$. [b] Determined from the lowest energy absorption edge of the thin film UV/Nis spectrum, with error margin estimated to be $\pm 0.08 \mathrm{eV}$.

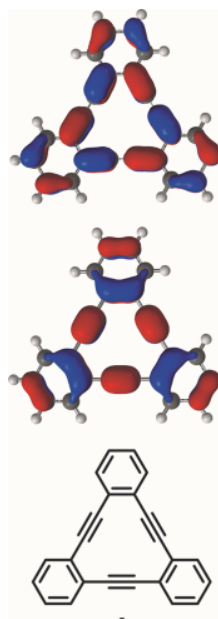

1
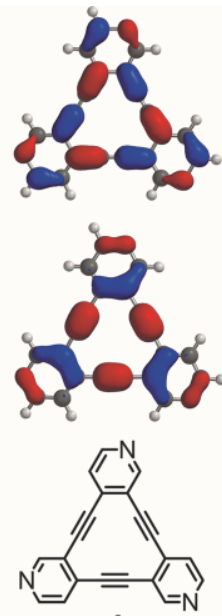

4
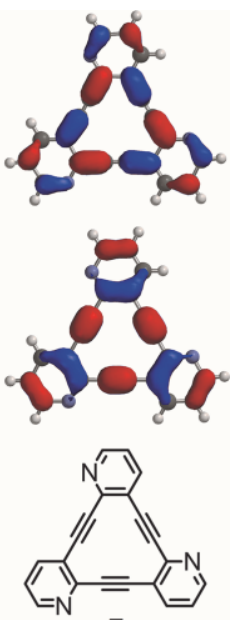

5
Figure 2. Calculated FMO surfaces of 1, 4 and 5, showing LUMO (upper) and HOMO (lower) plots, and molecular schematics at bottom.

The LUMO surfaces of the benzene rings of 1, $\mathbf{2}$ and $\mathbf{3}$ are all contracted or nodal at the aryl carbon atoms ortho- to the ethynes. Those of the pyridines of 2-4 are all nodal or virtually nodal at the carbon lying between the nitrogen and alkyne (i.e. C2).

On the other hand, the HOMO pyridine rings of 2-4 possess nodes at the $\mathrm{C} 5$ carbon atoms (i.e. the carbon atoms that lie meta- to the nitrogen that are not part of the inner $12-\pi$ DBA ring). The FMO surfaces of $\mathbf{5}$ are strikingly similar to those of $\mathbf{4}$, and in the former case, the orbital nodes within the HOMO lie at the pyridine nitrogen atoms, which are also denuded of some orbital volume in the corresponding LUMO. Overall, the HOMO and LUMO surfaces of the dehydropyridyl[12]annulenes 2-5 are very similar, exhibiting only minor relative disparities related more to the differences between the phenyl and pyridine rings.

Although a synthesis for $\mathbf{5}$ and its physicochemical properties remain unreported, the calculated presence of nodes on the HOMO nitrogen atoms suggests that it would be a poorer donor ligand for metal ion complexation than 4. By contrast, the HOMO of the $16-\pi$ electron macrocyclic ring of dehydrodibenzodipyrido[16]annulene $\mathbf{6}$ (Supporting Information) is less well conjugated than in 1-5 due to its lack of planarity. The diminished orbital surfaces and nodes at the 2,5-pyridine carbon atoms of the FMOs of 6 however, follows a similar pattern to that observed for the planar cycles 1-5.

\section{Electrochemical Study of 4}

The novel conjugation of [12]DBAs highlighted by theoretical studies leads to the expectation that they would exhibit interesting electronic properties, and indeed, sporadic investigations into the electrochemistry of these macrocycles have been reported. The first published cyclic voltammetric (CV) study of a [12]DBA was that of 1, which showed two reversible one electron reduction waves in THF. ${ }^{[1]}$ The [12]DBA skeleton was however found to be unstable to a second reduction if the reduction was performed chemically. ${ }^{[58]}$ Further studies have since been reported for [12]DBAs functionalized with CN, F, and COOMe acceptor, and 
$\mathrm{NR}_{2}$ and OMe donor groups, ${ }^{[42,47]}$ and [12]DBAs variously functionalized with ethynyl substituents. ${ }^{[13,59]}$ In accordance with the conclusions from theoretical studies, ${ }^{[42]}$ acceptor substituents facilitate reduction of the [12]DBA ring system relative to $\mathbf{1}$, while donor functionality enables oxidation processes to occur. Ethynyl substituents stabilize the [12]DBA ring to reduction relative to 1. However, no examples were observed where both reversible reduction and oxidation were possible within the same system.

In the light of these results, we decided to perform an electrochemical study on the all-pyrido derivative $\mathbf{4}$, in order to further investigate the electronic properties of the most electron-accepting of the macrocycles investigated in this work. The CV of $\mathbf{4}$ was therefore recorded (Figure 3), and found to display two reversible reductions at $E^{\circ}=-1.60$ and $-1.90 \mathrm{~V}(\mathrm{Fc}+/ \mathrm{Fc})$. The generated dianion containing 14- $\pi$ electrons is therefore aromatic. By comparison, the half-wave potentials of 1 (in $\mathrm{CH}_{2} \mathrm{Cl}_{2}$ ), tricyano[12]DBA and perfluoro-[12]DBA (in 1,1,2,2-tetrachloroethane) were reported to be $-2.21,-1.7$ and $-1.7 \mathrm{~V}$ respectively. ${ }^{[42]}$ Thus, 4 appears to be a superior electron acceptor compared to the tricyano- and perfluoro-substituted systems, confirming that it would be a promising system for the development of functional electronic acceptors based upon [12]DBAs.

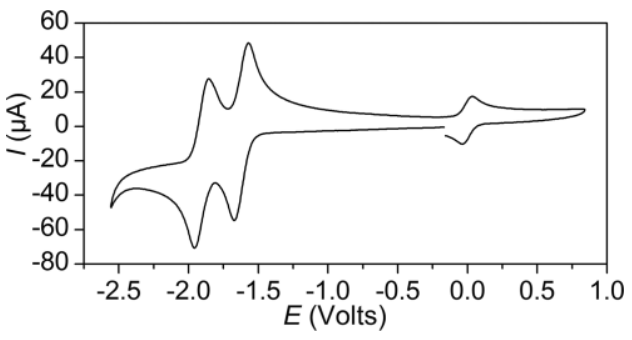

Figure 3. $\mathrm{CV}$ of 4 recorded in $\mathrm{CH}_{2} \mathrm{Cl}_{2}$ with $0.1 \mathrm{~mol} \mathrm{~L}^{-1} n \mathrm{Bu}_{4} \mathrm{NPF}_{6}$, at a scan rate of $0.2 \mathrm{~V} \mathrm{~s}^{-1}$.

\section{X-ray Crystal Structures of 2, 4, and 6}

An X-ray crystal structural analysis of the all-pyrido trimer $\mathbf{4}$ was performed on crystals grown by slow evaporation of a concentrated $\mathrm{CDCl}_{3}$ solution, and unambiguously demonstrated the cyclic nature of the molecule (Figure 4). The macrocycle is essentially planar despite slight crystal packing distortions with intramolecular N-N distances lying within the range 9.00-9.05.

Notably, 4 crystallizes as a solvate in which each macrocycle forms a single oblique hydrogen-bond of $2.31 \AA$ with a $\mathrm{CHCl}_{3}$ molecule. As in the X-ray crystal structure of $1,{ }^{[60]}$ the molecules of $\mathbf{4}$ are not arranged in the form of vertical stacks, which may have been expected for such a planar structure. Instead, they form layers as defined by the $b$-axis, in which the macrocycles are tilted relative to each other, and lie in staggered positions relative to those in directly adjacent layers. The $\mathrm{CHCl}_{3}$ molecules fill the interstices between the macrocycle layers with the result that there are few intermolecular $\pi-\pi$ contacts. The closest approach is between the $\mathrm{C} 15(\mathbf{4})$ and $\mathrm{C} 16\left(\mathbf{4}^{\prime}\right)$ of the pyridines that form an $\mathrm{H}$-bond with the included $\mathrm{CHCl}_{3}$, with an intermolecular C15-C16 distance of $3.245 \AA$. The crystal packing therefore appears to be dominated by the accommodation of the $\mathrm{CHCl}_{3}$ molecules; a factor which may significantly contribute to the slight deviation of $\mathbf{4}$ from complete planarity. ${ }^{[61]}$

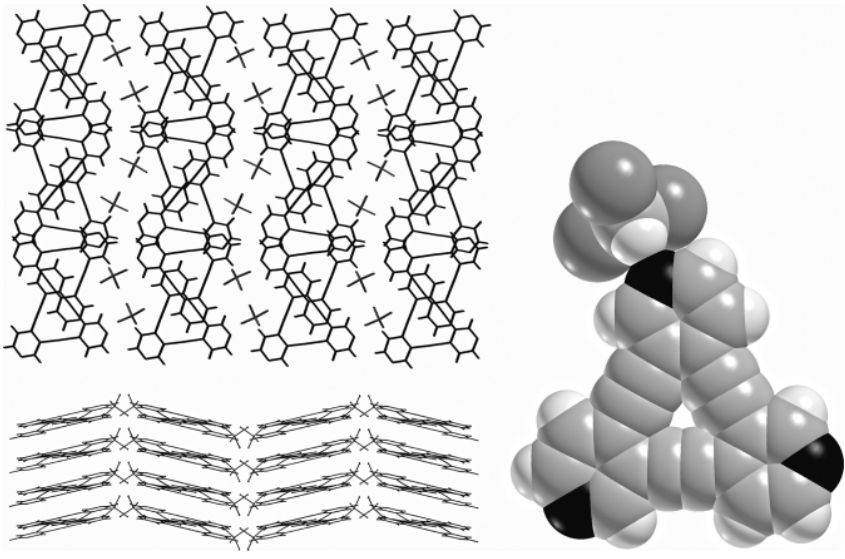

Figure 4. Crystal packing of $\mathbf{4}$ showing alternate parallel channels of macrocycles and included $\mathrm{CHCl}_{3}$ solvent: View perpendicular to $a-c$ plane showing two layers for clarity; upper left. View along the $a$-axis showing zig-zag arrangement of tilted sheets of 4; lower left. Space-filling representation of a single molecule of $\mathbf{4}$ with obliquely $\mathrm{H}$-bonded $\mathrm{CHCl}_{3}$; right.

Hot concentrated solutions of $\mathbf{2}$ in MeCN develop paper-thin yellow plates upon cooling, which were unambiguously confirmed to be the monopyridyl [12]annulene upon X-ray crystal structural analysis (Figure 5). At the molecular level, the macrocycles are associated into $\pi-\pi$ stacked pairs with a closest Van der Waals contact of $3.368 \AA$ (C1 - C25). Interestingly, the pyridine rings of each $\pi-\pi$ dimer lie next to each other with a parallel dipole alignment, although offset to minimize repulsive effects, with an inter-dimer N1 - N2 distance of $3.529 \AA$. The $\pi-\pi$ dimers are further packed into a 2-dimensional herringbone motif in the $a-b$ plane which is compacted together by various edge-to-face interactions. In the third dimension, the herringbone sheets are stratified into parallel layers that interact with each other via phenyl H - N2 hydrogen bonds of $2.54 \AA$, and various phenyl ring edge-to-face interactions as well as T-shaped hydrogen bonds between the comparatively acidic hydrogen ortho- to the pyridine $\mathrm{N} 1$ and a triple bond comprising the $\mathrm{C} 45$ - $\mathrm{C} 46$ carbon atoms (ethyne C45-pyH3 distance $=2.72 \AA$, ethyne C46-pyH3 = $2.76 \AA$ )
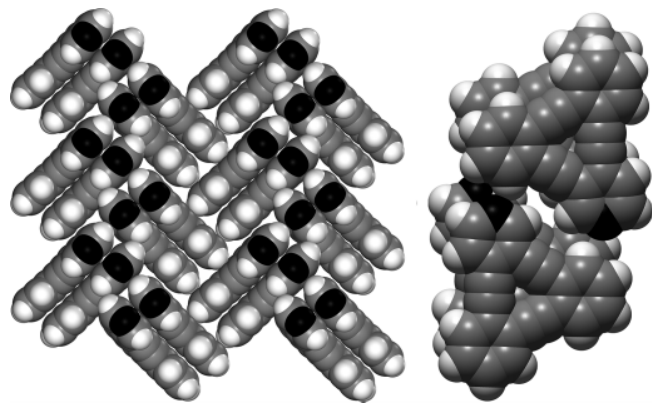

Figure 5. Crystal packing of $\mathbf{2}$ in the $a-b$ plane showing herringbone arrangement of $\pi-\pi$ stacked dimers (left); hydrogen bonded pair of $\pi-\pi$ stacked dimers (right).

After chromatographic purification of the $\mathbf{3}$ obtained from the reaction of entry 3 , Table 1 , the product was washed with $n$ hexane, which upon evaporation yielded a small cluster of crystals. One of these crystals diffracted X-rays sufficiently to enable 
unambiguous identification of the product as that of $\mathbf{6}$ incorporating two pyridine and two benzene rings (Scheme 2, Figure 6), i.e. the isomer in which the nitrogen atoms are positioned on opposite sides of the macrocyclic ring.
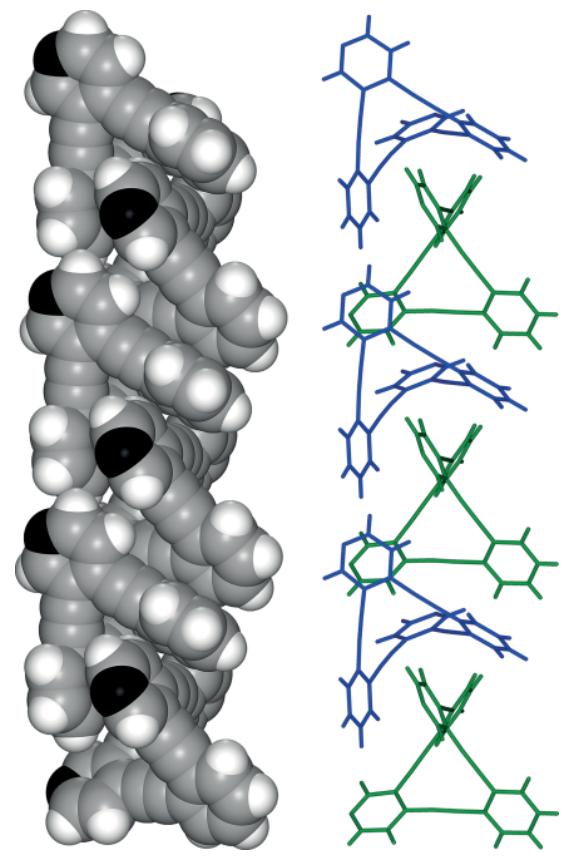

Figure 6. Space-filling representation of interdigitated column of $\mathbf{6}$ that propagates along the $b$-axis, left. Stick representation of column of $\mathbf{6}$ showing $A B A B A B$ sequence of receptor (blue) and guest (green) cycles; right.

As expected, the structure and conformation of $\mathbf{6}$ is similar to the hydrocarbon analogue dehydrotetrabenzo[16]annulene, ${ }^{[62]}$ in that it is a folded molecule with two V-shaped pockets on each side of the macrocyclic ring. Although $\mathbf{6}$ crystallizes in the same space group as the polymorph of dehydrotetrabenzo[16]annulene which was crystallized from $\mathrm{CHCl}_{3}{ }^{[62]} \mathbf{6}$ is instead packed into columns. Within each column, the molecules of $\mathbf{6}$ are alternately interdigitated into an $A B A B$ repeat sequence, where the pockets either side of one cycle each act as receptor for a pyridyl ring of its two adjacent neighbors (Figure 6). Thus, into the phenyl terminated $\mathrm{V}$-shaped pocket of the receptor cycle is nestled a pyridyl ring of the adjacent guest cycle; the ensemble being stabilized by a (Ph)C28-(Py)C47 $\pi-\pi$ contact of $3.375 \AA$ and a (ethyne)C6-(Ph)H42 contact of $2.89 \AA$. Into the other, pyridyl ring terminated pocket of the receptor cycle lies the other pyridyl ring of the opposite adjacent guest cycle such that it makes a preferential facial (Py)C1-(Py)C32 $\pi-\pi$ contact of $3.364 \AA$. The intramolecular $\mathrm{N}-\mathrm{N}$ distance of the receptor cycles is $9.072 \AA$, and $8.634 \AA$ for the guest cycles, reflecting the widening of the $\mathrm{V}$-shaped cavity of the receptor upon aromatic guest inclusion.

Viewed perpendicular to the $a-c$ plane, the columns of $\mathbf{6}$ are packed into rows that are held together by numerous face-toface $\pi-\pi$ interactions as well as aromatic edge-to-face contacts. The molecular packing within the columns of $\mathbf{6}$ therefore suggest that this tetra-aryl system may offer potential as a building block for the development of novel receptor architectures for specific aromatic guest inclusion.

\section{Conclusions}

A one-pot synthesis of asymmetric dehydrobenzopyrido[12]annulenes $\mathbf{2}$ and $\mathbf{3}$ via a mixed ethynylcuprate Stephens-Castro mediated cyclotrimerization has been successfully accomplished, confirming that this approach may afford a much more direct method of access to asymmetrically functionalized [12]DBAs compared to that of multistep sequential pathways.

DFT calculations and spectroscopic studies on 1-4 revealed that successive incorporation of nitrogen heteroatoms into the dehydrotriaryl[12]annulene framework of $\mathbf{1}$ has a negligible effect upon the HOMO - LUMO energy gap, in contrast to the electronic effects of external donor/acceptor substituents on 1. ${ }^{[42]}$ However, a proportional decrease in the energy of both HOMOs and LUMOs with increasing nitrogen content is observed, supporting the expectation that this increases the electron accepting ability of this macrocyclic system. The electrochemical properties of $\mathbf{4}$ were also in agreement with the theoretical calculations in exemplifying the potential of dehydropyrido[12]annulenes as promising electroactive platforms for the construction of electronically conjugated coordination scaffolds. Finally, the X-ray crystal structures of 2, 4 and tetra-aryl byproduct $\mathbf{6}$ unambiguously confirmed their proposed cyclic structural formulations, and in the latter two cases exhibited extended intermolecular packing motifs of interest for the design of organic semiconductor materials.

Further investigations are in progress in order to define the scope and utility of the one-pot mixed-coupling StephensCastro cyclotrimerization approach for the direct generation of asymmetric [12]DBAs, and the use of $\mathbf{2}$ and $\mathbf{3}$ for the generation of hybrid coordination materials.

\section{Experimental Section}

Material and Methods: All reactions were performed under argon using standard inert atmosphere and Schlenk techniques with glassware heat dried directly before use. The starting materials $7^{[39]}$ and $\mathbf{9}^{[52]}$ were prepared as reported, and the Cul (98\%), tBuOK (sublimed, $99.99 \%$ ), anhydrous pyridine and the $\mathrm{CH}_{2} \mathrm{Cl}_{2}$ used in the spectroscopic measurements ( $99.5 \%$ purity with an $\mathrm{H}_{2} \mathrm{O}$ content $<0.03 \%$ ) were obtained from commercial sources. The alumina chromatography was performed on neutral and basic Aluminium Oxide 90 (activity 1) that had been adjusted to the required activity by the addition of the appropriate quantity of distilled water, according to the Brockmann scale. ${ }^{[63]}$ All ${ }^{1} \mathrm{H}$ and ${ }^{13} \mathrm{C}$ NMR spectra performed in $\mathrm{CDCl}_{3}$ were referenced to the $\mathrm{CHCl}_{3}$ solvent peaks at 7.26 and $77.0 \mathrm{ppm}$ respectively. The partial peak assignment of the ${ }^{1} \mathrm{H}$ NMR spectra of $\mathbf{2}$ and 3 were based upon ${ }^{1} \mathrm{H}-{ }^{-1} \mathrm{H}$ COSY measurements. Melting points were measured on an Orthoplan Leitz microscope fitted with a Mettler FP82 hotstage.

\section{Synthesis and Isolation of 1-4 and 6}

The quantities of reagents used for the mixed cyclization reactions presented in entries 1-3 of Table 1 are detailed below. In all cases $0.125 \mathrm{~g}\left(5.46 \times 10^{-4} \mathrm{~mol}\right)$ of 9 was used. For entry 1: $0.124 \mathrm{~g}$ $\left(5.46 \times 10^{-4} \mathrm{~mol}\right) 7,0.208 \mathrm{~g}\left(1.09 \times 10^{-3} \mathrm{~mol}\right) \mathrm{Cul}$ and $0.123 \mathrm{~g}$ $\left(1.1 \times 10^{-3} \mathrm{~mol}\right) \mathrm{tBuOK}$ in a total volume of $20 \mathrm{~mL}$ of pyridine were used, to provide a 1:1:2:2 stoichiometry of $7 / 9 / \mathrm{Cul} / \mathrm{tBuOK}$. For entry 2: $0.248 \mathrm{~g}\left(1.09 \times 10^{-3} \mathrm{~mol}\right) 7,0.312 \mathrm{~g}\left(1.64 \times 10^{-3} \mathrm{~mol}\right) \mathrm{Cul}$ and 0.184 $\left(1.64 \times 10^{-3} \mathrm{~mol}\right) \mathrm{tBuOK}$ in a total volume of $30 \mathrm{~mL}$ of pyridine were employed, to afford a 2:1:3:3 stoichiometry of 7/9/Cul/tBuOK. For 
entry 3: $0.496 \mathrm{~g}\left(2.18 \times 10^{-3} \mathrm{~mol}\right) 7,0.520 \mathrm{~g}\left(2.73 \times 10^{-3} \mathrm{~mol}\right) \mathrm{Cul}$ and $0.306 \mathrm{~g}\left(2.73 \times 10^{-3} \mathrm{~mol}\right) \mathrm{tBuOK}$ in a total volume of $50 \mathrm{~mL}$ of pyridine were used, to give a 4:1:5:5 stoichiometry of 7/9/Cul/tBuOK.

For each experiment, a dried 2-necked $100 \mathrm{~mL}$ round bottomed flask containing the appropriate quantity of $\mathrm{Cul}$ and $t \mathrm{BuOK}$, was fitted with a reflux condenser in one neck and a stopcock adaptor with a rubber septum into the other, and evacuated and backfilled with argon four times. The appropriate quantity of pyridine was added by syringe; the volume increasing with increasing amounts of metal salts in order to maintain identical concentrations for each reaction. The mixture was briefly ultrasonicated and then stirred at ambient temperature for $1 \mathrm{~h}$. Ethynylpyridine $9\left(0.125 \mathrm{~g}, 5.46 \times 10^{-4} \mathrm{~mol}\right)$ and the appropriate quantity of $\mathbf{7}$ were weighed directly into a dried Schlenk, which was then fitted with a rubber septum and cooled to $0{ }^{\circ} \mathrm{C}$ in an ice-bath to minimize evaporative losses of $\mathbf{7}$ under vacuum. The Schlenk was evacuated and backfilled with argon four times, pyridine (2-5 mL) added, and the solution transferred to the $t \mathrm{BuOCu}$ reaction via syringe. The Schlenk was then washed with two further aliquots of pyridine, which were also transferred via syringe to the reaction flask. The reaction was stirred at ambient temperature for $18 \mathrm{~h}$, during which time a red-orange suspension slowly formed. The mixed cyclization was effected by heating the stirred reaction in a bath at $140{ }^{\circ} \mathrm{C}$ for $24 \mathrm{~h}$, during which time the reaction suspension became black in color. All solvent was removed under reduced pressure on a water bath and the residue partitioned between $\mathrm{CH}_{2} \mathrm{Cl}_{2}(50 \mathrm{~mL})$ and $20 \mathrm{~mL}$ of dilute aq. $\mathrm{KCN}(5 \mathrm{~g} / 100 \mathrm{~mL})$. The aqueous phase was extracted with further portions of $\mathrm{CH}_{2} \mathrm{Cl}_{2}(5 \times 50 \mathrm{~mL})$, and the combined organic extracts dried (anhydrous $\mathrm{Na}_{2} \mathrm{SO}_{4}$ ), gravity filtered, and the solvent distilled off on a water bath.

The remaining solid was then chromatographed on a column of neutral alumina (Brockmann grade III) eluting with $\mathrm{CH}_{2} \mathrm{Cl}_{2}$. The 1 eluted first, followed in sequence by $\mathbf{2 , 3}$ and lastly $\mathbf{4}$ if present. The $\mathbf{1}$ was further purified by column chromatography twice on flash silica, eluting with $5 \% \mathrm{CH}_{2} \mathrm{Cl}_{2} / n$-hexane and finally sublimed under vacuum at $125^{\circ} \mathrm{C} / 0.001$ Torr to obtain a product pure by ${ }^{1} \mathrm{H}$ NMR spec-

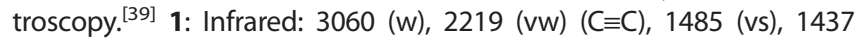
(mw), $1086(\mathrm{mw}), 951(\mathrm{mw}) 745$ (vs), $583 \mathrm{~cm}^{-1}(\mathrm{mw})$. UV/Vis $\left(\mathrm{CH}_{2} \mathrm{Cl}_{2}\right)$ : $\lambda_{\max }(\varepsilon)=259\left(2.9 \times 10^{4}\right), 266\left(4.5 \times 10^{4}\right), 274\left(1.4 \times 10^{5}\right), 281$ $\left(1.2 \times 10^{5}\right), 290\left(3.7 \times 10^{5}\right), 321\left(5.1 \times 10^{3}\right), 332\left(6.2 \times 10^{3}\right), 344 \mathrm{~nm}$ $\left(9.4 \times 10^{3} \mathrm{M}^{-1} \mathrm{~cm}^{-1}\right)$; Luminescence $\lambda_{\text {max }}\left(4 \times 10^{-6} \mathrm{~mol} \mathrm{~L}^{-1}\right.$ in $\left.\mathrm{CH}_{2} \mathrm{Cl}_{2}\right)$ : 466, 482, 489(sh), $509 \mathrm{~nm}$.

The $\mathbf{2}$ was further purified by repeated column chromatography on neutral alumina (Brockmann grade II) eluting with $\mathrm{CH}_{2} \mathrm{Cl}_{2}$, although it was discovered at a later stage that it was better purified by flash chromatography on silica, eluting with $\mathrm{CH}_{2} \mathrm{Cl}_{2}$. The product was then sublimed under vacuum $\left(120-130{ }^{\circ} \mathrm{C} / 0.001\right.$ Torr) to yield pure 2 as a yellow powder (M.p.: $207-209^{\circ} \mathrm{C}$ ). The $\mathbf{3}$ was further twice chromatographed on neutral alumina (Brockmann grade III) eluting with $\mathrm{CH}_{2} \mathrm{Cl}_{2}$ and then sublimed under vacuum (120-130 ${ }^{\circ} \mathrm{C} / 0.001$ Torr). The product was suspended in 5-13 mL $n$-hexane, briefly boiled, left to stand for $24 \mathrm{~h}$ and the solvent decanted off. The remaining solid was washed with $n$-hexane $(3 \times 1 \mathrm{~mL})$, and finally heated to $90{ }^{\circ} \mathrm{C}$ under a gentle stream of nitrogen to drive off included solvent, yielding 3 as a yellow solid (M.p.: $256-257^{\circ} \mathrm{C}$ ). This compound could also be recrystallized from MeCN. In the case of the reaction in entry 3 of Table 1, the product was washed with a small volume of $n$-hexane before vacuum sublimation. Slow evaporation of the $n$-hexane extract in the dark yielded a small cluster of crystals $(<0.4 \mathrm{mg},<1 \%)$, which were identified as tetramer 6 upon X-ray crystallographic and mass spectral analyses (see below). The $\mathbf{4}$ when present was further purified by brief ultrasonication in $\mathrm{MeCN}(3 \mathrm{~mL})$, isolation by filtration under vacuum, washing with $\mathrm{MeCN}(3 \times 0.5 \mathrm{~mL})$ and finally drying in a gentle stream of nitrogen at $90{ }^{\circ} \mathrm{C}$. The ${ }^{1} \mathrm{H}$ NMR of $\mathbf{4}$ was as described. ${ }^{[52]}$ 2: ${ }^{1} \mathrm{H}$ NMR $\left(5 \times 10^{-3} \mathrm{~mol} \mathrm{~L}^{-1}, \mathrm{CDCl}_{3}, 400.13 \mathrm{MHz}, 21^{\circ} \mathrm{C}\right)$ : $\delta=8.531\left[\mathrm{~d},{ }^{5} \mathrm{~J}(2,5)=0.7 \mathrm{~Hz}, 1 \mathrm{H}\right.$; Py H2] $\delta=8.364\left[\mathrm{~d},{ }^{3} \mathrm{~J}(6,5)=\right.$ $5.1 \mathrm{~Hz}, 1 \mathrm{H} ; \mathrm{Py} \mathrm{H6}], \delta=7.356\left(\mathrm{~m}, 4 \mathrm{H} ; \mathrm{Ph} \mathrm{H} 3, \mathrm{H} 6 / \mathrm{H}^{\prime}, \mathrm{H}^{\prime}\right), \delta=7.220$ $\left(\mathrm{m}, 4 \mathrm{H} ; \mathrm{Ph} \mathrm{H} 4, \mathrm{H} 5 / \mathrm{H}^{\prime}{ }^{\prime}, \mathrm{H} 5^{\prime}\right), \delta=7.167\left[\mathrm{dd},{ }^{3} J(5,6)=5.1 \mathrm{~Hz},{ }^{5} J(5,2)=\right.$ $0.9 \mathrm{~Hz}, 1 \mathrm{H}$; Py H5]. ${ }^{13} \mathrm{C}$ NMR $\left(2 \times 10^{-2} \mathrm{~mol} \mathrm{~L}^{-1}, \mathrm{CDCl}_{3}, 100.61 \mathrm{MHz}\right.$, $\left.22{ }^{\circ} \mathrm{C}\right): \delta=152.1,148.7,134.3,132.6,132.24,132.17,132.0,129.6$, $129.0,128.7,128.6,127.4,126.8,126.0,125.4,124.8,122.8,97.3(-C \equiv)$, $95.8(-C \equiv), 93.1(-C \equiv), 92.6(-C \equiv), 90.2(-C \equiv), 89.8$ ppm (-C $\equiv)$; Infrared: $3057(w), 3027(w), 2923(w), 2217(m w)(C \equiv C), 1575(m), 1486(s)$, $1437(\mathrm{mw}), 1400(\mathrm{~m}), 1267(\mathrm{mw}), 1154(\mathrm{mw}), 1087(\mathrm{mw}), 838(\mathrm{~m})$, 831 (mw), 752 (vs), $706(\mathrm{mw}), 668(\mathrm{mw}), 579 \mathrm{~cm}^{-1}(\mathrm{~s})$. UV/Vis $\left(\mathrm{CH}_{2} \mathrm{Cl}_{2}\right)$ : $\lambda_{\max }(\varepsilon)=274\left(9.1 \times 10^{4}\right), 281\left(1 \times 10^{5}\right), 290\left(2 \times 10^{5}\right), 322\left(7.3 \times 10^{3}\right)$, $333\left(7.5 \times 10^{3}\right), 346 \mathrm{~nm}\left(1.0 \times 10^{4} \mathrm{M}^{-1} \mathrm{~cm}^{-1}\right)$; Luminescence $\lambda_{\max }(4 \times$ $10^{-6} \mathrm{~mol} \mathrm{~L}^{-1}$ in $\left.\mathrm{CH}_{2} \mathrm{Cl}_{2}\right): 497,524(\mathrm{sh}) \mathrm{nm}$; High Res. ESI MS $(\approx 1: 0.1$ $\mathrm{CH}_{2} \mathrm{Cl}_{2} / \mathrm{MeOH}$ ): $\mathrm{m} / \mathrm{z}$ (\%): calcd. for $\mathrm{C}_{23} \mathrm{H}_{12} \mathrm{~N}$ : 302.0964 , found 302.0964 (100) $\left[\mathrm{M}+\mathrm{H}^{+}\right]$. 3: ${ }^{1} \mathrm{H}$ NMR $\left(1 \times 10^{-2} \mathrm{~mol} \mathrm{~L}^{-1}, \mathrm{CDCl}_{3}, 400.13 \mathrm{MHz}\right.$, $\left.20{ }^{\circ} \mathrm{C}\right):\left\{\delta=8.568\left(\mathrm{~d},{ }^{5} \mathrm{~J}=0.7 \mathrm{~Hz}, 1 \mathrm{H}\right), \delta=8.563\left(\mathrm{~d},{ }^{5} \mathrm{~J}=0.7 \mathrm{~Hz}, 1 \mathrm{H}\right)\right\}$ Py H2/Hz', $\left\{\delta=8.437\left(\mathrm{~d},{ }^{3} J=5.1 \mathrm{~Hz}, 1 \mathrm{H}\right), \delta=8.413\left(\mathrm{~d},{ }^{3} \mathrm{~J}=5.1 \mathrm{~Hz}, 1\right.\right.$ H) $\}$ Py H6/H6', $\delta=7.394$ (m, $2 \mathrm{H} ; \mathrm{Ph} \mathrm{H} 3, \mathrm{H} 6), \delta=7.267$ (m, $2 \mathrm{H}$; Ph $\mathrm{H} 4, \mathrm{H} 5),\left\{\delta=7.210\left(\mathrm{dd},{ }^{3} \mathrm{~J}=5.0 \mathrm{~Hz},{ }^{5} \mathrm{~J}=0.7 \mathrm{~Hz}, 1 \mathrm{H}\right), \delta=7.202(\mathrm{dd}\right.$, $\left.\left.{ }^{3} \mathrm{~J}=5.0 \mathrm{~Hz},{ }^{5} \mathrm{~J}=0.8 \mathrm{~Hz}, 1 \mathrm{H}\right)\right\} \mathrm{Py} \mathrm{H} 5 / \mathrm{H}^{\prime} .{ }^{13} \mathrm{C} \mathrm{NMR}\left(2 \times 10^{-2} \mathrm{~mol} \mathrm{~L}^{-1}\right.$, $\left.\mathrm{CDCl}_{3}, 100.61 \mathrm{MHz}, 2{ }^{\circ} \mathrm{C}\right): \delta=152.6,152.3,149.7,148.9,135.0,133.6$, $132.8,132.3,129.9,129.1,126.8,125.4,125.0,124.7,122.8,121.6,97.6$ $(-C \equiv), 95.5(-C \equiv), 94.1(-C \equiv), 93.0(-C \equiv), 90.1 \quad(-C \equiv), 90.0$ ppm (-C $\equiv)$; Infrared: $3057(w), 3026(w), 2920(w), 2223(m)(C \equiv C), 2203(\mathrm{mw})(C \equiv C)$, $1575(\mathrm{~s}), 1529(\mathrm{mw}), 1487(\mathrm{~s}), 1395(\mathrm{~m}), 1273(\mathrm{mw}), 1181(\mathrm{mw}), 1091$ $(\mathrm{mw}), 1049(\mathrm{mw}), 891(\mathrm{mw}), 837(\mathrm{~s}), 828(\mathrm{~s}), 769(\mathrm{~s}), 755(\mathrm{~s}), 746(\mathrm{~s})$, $716(\mathrm{~m}), 680(\mathrm{mw}), 604(\mathrm{mw}), 583(\mathrm{vs}), 567 \mathrm{~cm}^{-1}(\mathrm{~m})$. UV/Vis $\left(\mathrm{CH}_{2} \mathrm{Cl}_{2}\right)$ : $\lambda_{\max }(\varepsilon)=275(\mathrm{sh})\left(8.5 \times 10^{4}\right), 280$ (sh) $\left(9.3 \times 10^{4}\right), 289\left(1.6 \times 10^{5}\right), 320$ $\left(1.1 \times 10^{4}\right), 331\left(1.2 \times 10^{4}\right), 344 \mathrm{~nm}\left(1.6 \times 10^{4} \mathrm{M}^{-1} \mathrm{~cm}^{-1}\right)$; Luminescence $\lambda_{\max }\left(4 \times 10^{-6} \mathrm{~mol} \mathrm{~L}^{-1}\right.$ in $\left.\mathrm{CH}_{2} \mathrm{Cl}_{2}\right): 501 \mathrm{~nm}$; High Res. ESI MS $(\approx 1: 0.1$ $\mathrm{CH}_{2} \mathrm{Cl}_{2} / \mathrm{MeOH}$ ): $\mathrm{m} / \mathrm{z}$ (\%): calcd. for $\mathrm{C}_{22} \mathrm{H}_{11} \mathrm{~N}_{2}$ : 303.0917, found 303.0907 (100) $\left[M+\mathrm{H}^{+}\right]$

6: UV/Vis $\left(\mathrm{CH}_{2} \mathrm{Cl}_{2}\right): \lambda_{\max }(\varepsilon)=272\left(4.4 \times 10^{4} \mathrm{M}^{-1} \mathrm{~cm}^{-1}\right)$; High Res. ESI MS ( $\approx$ 1:0.1 $\mathrm{CH}_{2} \mathrm{Cl}_{2} / \mathrm{MeOH}$ ): $\mathrm{m} / \mathrm{z}$ (\%): calcd. for $\mathrm{C}_{30} \mathrm{H}_{15} \mathrm{~N}_{2}$ : 403.1230, found 403.1223 (100) $\left[M+\mathrm{H}^{+}\right]$. Calcd. for $\mathrm{C}_{30} \mathrm{H}_{14} \mathrm{LiN}_{2}$ : 409.1312, found $409.1308(46)\left[M+\mathrm{Li}^{+}\right]$.

CCDC 1557045 (for 2), 1557044 (for 4), and 1557046 (for 6) contain the supplementary crystallographic data for this paper. These data can be obtained free of charge from The Cambridge Crystallographic Data Centre.

Supporting Information (see footnote on the first page of this article): Physical methods (UV/Vis and luminescence spectroscopic and electrochemistry data, ESI mass spectra, and calculated molecular ion masses for $6,{ }^{1} \mathrm{H}$ and ${ }^{13} \mathrm{C}$ NMR spectra of $\mathbf{2}$ and 3), general X-ray experimental information, crystallographic data, refinements, and ORTEP representations for $\mathbf{2}, \mathbf{4}$, and $\mathbf{6}$ with atom numbering, FMO surfaces of $\mathbf{2}, \mathbf{3}$, and $\mathbf{6}$, calculated structure Cartesian coordinates for 1-6, and references (continued).

\section{Acknowledgments}

The Centre National de la Recherche Scientifique and the Institut Charles Sadron is acknowledged for financial support (P. N. W. B). Dr. B. Heinrich of the Institut de Physique et Chimie des Matériaux de Strasbourg (IPCMS), Strasbourg, is thanked for recording the melting points of $\mathbf{2}$ and 3. Professor J. D. Wallace of Nottingham Trent University is thanked for insightful and helpful discussions. 
Keywords: Alkynes · Annulenes · Cross-coupling · Cuprates Macrocycles

[1] Named in the literature as tribenzocyclyne and tribenzocyclotriyne (TBC), benzo[12]annulene, dehydrobenzo[12]annulene and trisdehydrotribenzo[12]annulene ([12]DBA), tribenzohexadehydro[12]annulene, hexadehydrotribenzo[12]annulene, hexadehydrotribenzo[a,e,i][12]annulene, 5,6,11,12, 17,18-hexadehydrotribenzo[a,e,i]cyclododecene (TBC), 1,2:5,6:9,10-tribenzocyclododeca-1,5,9-triene-3,7,11-triyne and 1,2:5,6:9,10-tribenzo-3,7,11tridehydro[12]annulene. For the sake of brevity and due to frequent use in the literature, this class of compound is herein referred to as dehydrobenzo[12]annulene or the abbreviation [12]DBA.

[2] J. Jusélius, D. Sundholm, Phys. Chem. Chem. Phys. 2001, 3, 2433-2437.

[3] A. J. Matzger, K. P. C. Vollhardt, Tetrahedron Lett. 1998, 39, 6791-6794.

[4] K. Tahara, T. Yoshimura, M. Sonoda, Y. Tobe, R. V. Williams, J. Org. Chem. 2007, 72, 1437-1442.

[5] N. Narita, S. Nagai, S. Suzuki, Phys. Rev. B 2001, 64, 245408-1-245408-7.

[6] N. Narita, S. Nagai, S. Suzuki, K. Nakao, Phys. Rev. B 2000, 62, 11 146-11 151.

[7] U. H. F. Bunz, Y. Rubin, Y. Tobe, Chem. Soc. Rev. 1999, 28, 107-119.

[8] N. Narita, S. Nagai, S. Suzuki, K. Nakao, Phys. Rev. B 1998, 58, 11 009-11 014.

[9] R. H. Baughman, H. Eckhardt, M. Kertesz, J. Chem. Phys. 1987, 87, 66876699.

[10] W. J. Youngs, C. A. Tessier, J. D. Bradshaw, Chem. Rev. 1999, 99, 3153-3180.

[11] J. D. Ferrara, A. A. Tanaka, C. Fierro, C. A. Tessier-Youngs, W. J. Youngs, Organometallics 1989, 8, 2089-2098.

[12] J. D. Ferrara, C. A. Tessier-Youngs, W. J. Youngs, J. Am. Chem. Soc. 1985, 107, 6719-6721.

[13] K. Tahara, Y. Yamamoto, D. E. Gross, H. Kozuma, Y. Arikuma, K. Ohta, Y. Koizumi, Y. Gao, Y. Shimizu, S. Seki, K. Kamada, J. S. Moore, Y. Tobe, Chem. Eur. J. 2013, 19, 11251-11260.

[14] K. Tahara, T. Yoshimura, M. Ohno, M. Sonoda, Y. Tobe, Chem. Lett. 2007, 36, 838-839.

[15] M. Sonoda, Y. Sakai, T. Yoshimura, Y. Tobe, K. Kamada, Chem. Lett. 2004, 33, 972-973.

[16] C. A. Johnson II, Y. Lu, M. M. Haley, Org. Lett. 2007, 9, 3725-3728.

[17] T. Yoshimura, A. Inaba, M. Sonoda, K. Tahara, Y. Tobe, R. V. Williams, Org. Lett. 2006, 8, 2933-2936.

[18] M. lyoda, S. Sirinintasak, Y. Nishiyama, A. Vorasingha, F. Sultana, K. Nakao, Y. Kuwatani, H. Matsuyama, M. Yoshida, Y. Miyake, Synthesis 2004, 1527-1531.

[19] M. M. Haley, Pure Appl. Chem. 2008, 80, 519-532.

[20] O. Š. Miljanić, K. P. C. Vollhardt, G. D. Whitener, Synlett 2003, 29-34.

[21] J. M. Kehoe, J. H. Kiley, J. J. English, C. A. Johnson, R. C. Petersen, M. M. Haley, Org. Lett. 2000, 2, 969-972.

[22] K. Tahara, K. Kaneko, K. Katayama, S. Itano, C. H. Nguyen, D. D. D. Amorim, S. De Feyter, Y. Tobe, Langmuir 2015, 31, 7032-7040

[23] K. Tahara, J. Adisoejoso, K. Inukai, S. Lei, A. Noguchi, B. Li, W. Vanderlinden, S. De Feyter, Y. Tobe, Chem. Commun. 2014, 50, 2831-2833.

[24] J.-H. Kim, K. Tahara, J. Jung, S. De Feyter, Y. Tobe, Y. Kim, M. Kawai, J. Phys. Chem. C 2012, 116, 17082-17088.

[25] K. Tahara, E. Ghijsens, M. Matsushita, P. Szabelski, S. De Feyter, Y. Tobe, Chem. Commun. 2011, 47, 11459-11461.

[26] K. Tahara, S. Lei, J. Adisoejoso, S. De Feyter, Y. Tobe, Chem. Commun. 2010, 46, 8507-8525 and references cited therein.

[27] K. Tahara, K. Katayama, M. O. Blunt, K. Iritani, S. De Feyter, Y. Tobe, ACS Nano 2014, 8, 8683-8694.

[28] J. Adisoejoso, K. Tahara, S. Lei, P. Szabelski, W. Rzysko, K. Inukai, M. O. Blunt, Y. Tobe, S. De Feyter, ACS Nano 2012, 6, 897-903.

[29] K. Tahara, S. Lei, D. Mössinger, H. Kozuma, K. Inukai, M. Van der Auweraer, F. C. De Schryver, S. Höger, Y. Tobe, S. De Feyter, Chem. Commun. 2008, 3897-3899.

[30] K. Tahara, H. Yamaga, E. Ghijsens, K. Inukai, J. Adisoejoso, M. O. Blunt, S. De Feyter, Y. Tobe, Nat. Chem. 2011, 3, 714-719.

[31] K. Tahara, K. Inukai, J. Adisoejoso, H. Yamaga, T. Balandina, M. O. Blunt, S. De Feyter, Y. Tobe, Angew. Chem. Int. Ed. 2013, 52, 8373-8376; Angew. Chem. 2013, 125, 8531-8534.
[32] K. Schouteden, T. Ivanova, Z. Li, V. Iancu, K. Tahara, Y. Tobe, J. Adisoejoso, S. De Feyter, C. Van Haesendonck, E. Janssens, Chem. Commun. 2015, 51, 10917-10920.

[33] I. Hisaki, E. Kometani, H. Shigemitsu, N. Tohnai, M. Miyata, Synlett 2015, 26, 1601-1605.

[34] I. Hisaki, Y. Sakamoto, H. Shigemitsu, N. Tohnai, M. Miyata, S. Seki, A. Saeki, S. Tagawa, Chem. Eur. J. 2008, 14, 4178-4187.

[35] L. A. Baldwin, J. W. Crowe, M. D. Shannon, C. P. Jaroniec, P. L. McGrier, Chem. Mater. 2015, 27, 6169-6172.

[36] H. Yang, Y. Du, S. Wan, G. D. Trahan, Y. Jin, W. Zhang, Chem. Sci. 2015, 6, 4049-4053.

[37] I. D. Campbell, G. Eglinton, W. Henderson, R. A. Raphael, Chem. Commun. 1966, 4, 87-89.

[38] D. Zhang, C. A. Tessier, W. J. Youngs, Chem. Mater. 1999, 11, 3050-3057.

[39] D. Solooki, J. D. Ferrara, D. Malaba, J. D. Bradshaw, C. A. Tessier, W. J. Youngs, Inorg. Synth. 1997, 31, 122-128.

[40] J. D. Kinder, C. A. Tessier, W. J. Youngs, Synlett 1993, 149-150.

[41] I. Hisaki, H. Senga, H. Shigemitsu, N. Tohnai, M. Miyata, Chem. Eur. J. 2011, 17, 14348-14353.

[42] K. Tahara, T. Fujita, M. Sonoda, M. Shiro, Y. Tobe, J. Am. Chem. Soc. 2008, 130, 14339-14345.

[43] K. Tahara, S. Furukawa, H. Uji-i, T. Uchino, T. Ichikawa, J. Zhang, W. Mamdouh, M. Sonoda, F. C. De Schryver, S. De Feyter, Y. Tobe, J. Am. Chem. Soc. 2006, 128, 16613-16625.

[44] S. Takahashi, Y. Kuroyama, K. Sonogashira, N. Hagihara, Synthesis 1980, 627630.

[45] K. Sonogashira, Y. Tohda, N. Hagihara, Tetrahedron Lett. 1975, 16, 44674470.

[46] H. A. Staab, R. Bader, Chem. Ber. 1970, 103, 1157-1167.

[47] H. Shigemitsu, I. Hisaki, E. Kometani, D. Yasumiya, Y. Sakamoto, K. Osaka, T. S. Thakur, Akinori Saeki, S. Seki, F. Kimura, T. Kimura, N. Tohnai, M. Miyata, Chem. Eur. J. 2013, 19, 15366-15377.

[48] M. Dudič, l. Císařová, J. Michl, J. Org. Chem. 2012, 77, 68-74.

[49] H. A. Staab, F. Graf, Tetrahedron Lett. 1966, 7, 751-757.

[50] H. A. Staab, F. Graf, Chem. Ber. 1970, 103, 1107-1118.

[51] S. H. Seo, T. V. Jones, H. Seyler, J. O. Peters, T. H. Kim, J. Y. Chang, G. N. Tew, J. Am. Chem. Soc. 2006, 128, 9264-9265.

[52] P. N. W. Baxter, R. D.-Youcef, J. Org. Chem. 2005, 70, 4935-4953.

[53] It was more convenient to generate the $t \mathrm{BuOCu}$ in situ due to its air and water sensitivity.

[54] S. S. Y. Chui, M. F. Y. Ng, C.-M. Che, Chem. Eur. J. 2005, 11, 1739-1749 and references cited therein.

[55] A. D. Becke, J. Chem. Phys. 1993, 98, 5648-5652.

[56] C. Lee, W. Yang, R. G. Parr, Phys. Rev. B 1988, 37, 785-789.

[57] The DFT calculated band gaps for 1-4 were consistently 0.33-0.41 eV higher in energy than the experimentally determined solution optical band gaps derived from the lowest energy absorption edges from 360-450 nm shown in the magnified spectrum of Figure 1. However, the calculated band gaps corresponded more closely with the second lowest energy absorption edges at $350 \mathrm{~nm}$ seen in the upper left part of the magnified spectrum of Figure 1.

[58] D. Malaba, A. Djebli, L. Chen, E. A. Zarate, C. A. Tessier, W. J. Youngs, Organometallics 1993, 12, 1266-1276.

[59] A. Al Ouahabi, P. N. W. Baxter, J.-P. Gisselbrecht, A. De Cian, L. Brelot, N. Kyritsakas-Gruber, J. Org. Chem. 2009, 74, 4675-4689.

[60] H. Irngartinger, L. Leiserowitz, G. M. J. Schmidt, Chem. Ber. 1970, 103, 1119 1131.

[61] The influence of solvent on the crystallization of dehydrotribenzoro[12]annulenes is exemplified in a recent report, describing the preferential direction of the hydrogens of included $\mathrm{CHCl}_{3}$ into the cavity of the macrocycle, even when pyridine substituents are present; I. Hisaki, H. Senga, Y. Sakamoto, S. Tsuzuki, N. Tohnai, M. Miyata, Chem. Eur. J. 2009, 15, 13336-13340.

[62] i.e. $P 2_{1} / c$; See: D. Solooki, J. D. Bradshaw, C. A. Tessier, W. J. Youngs, R. F. See, M. Churchill, J. D. Ferrara, J. Organomet. Chem. 1994, 470, 231-236.

[63] B. S. Furniss, A. J. Hannaford, V. Rogers, P. W. G. Smith, A. R. Tatchell, Revised Vogel's Textbook of Organic Chemistry (Including Qualitative Organic Analysis), 4th ed.; Longman, London and New York, 1978, pp. 199-200.

Received: May 19, 2017 